\title{
Flupirtine: A Human Drug with Potential for Use in the Veterinary Field
}

\author{
${ }^{1}$ Mario Giorgi and ${ }^{2}$ Helen Owen \\ ${ }^{1}$ Department of Veterinary Clinics, Faculty of Veterinary Medicine, \\ University of Pisa, Via Livornese (lato monte) 1, San Piero a Grado 56010 Pisa, Italy \\ ${ }^{2}$ School of Veterinary Science, \\ The University of Queensland, Gatton Campus, Gatton, Queensland, 4343, Australia
}

Received 2012-09-03, Revised 2012-10-03; Accepted 2012-10-03

\begin{abstract}
Flupirtine is a nonopioid drug without antipyretic or antiphlogistic properties and with a favorable tolerability in humans. It constitutes a unique class within the group of nonsteroidal analgesics and displays a peculiar pharmacokinetic/dynamic profile that could have large potentialities of applications in the veterinary field. This review describes and evaluates the pharmacologic literature concerning flupirtine and addresses its potential in veterinary medicine.
\end{abstract}

Keywords: Animal Species, Painkiller Drug, Veterinary, Flupirtine

\section{INTRODUCTION}

The heterogenous group of nonopioid analgetic drugs can be divided into several classes according to their pharmacodynamic properties. Within this group, the Non-Steroidal Anti-Inflammatory Drugs (NSAIDs) constitute the largest drug family, followed by the coxibs. Increasingly, other drugs within the smaller classes are being used in pain therapy, often in combination with other drugs. Examples include the calcium channel antagonists, adrenoceptor agonists, gabapentin/pregabalin (these have structural homology with the neurotransmitter G-Aminobutyric Acid [GABA]), local anaesthetics, ligand-gated ion channel (TRPV1) agonists/antagonists and cannabinoid ligands (Hebbes and Lambert, 2011). Flupirtine (FL) belongs to the class of $N$-methyl-D-aspartate (NMDA) antagonists, although within this class it is considered atypical.

FL was initially synthesized by Degussa Pharma (Frankfurt/Main, Germany) and was first approved in the 1980s in Germany (Friedel and Fitton, 1993). Currently, it is marketed in several countries: Germany, Italy, Portugal, Russia, Slovakia, Estonia, Latvia, Lithuania, India, United States of America and Brazil.

\subsection{Chemical Properties}

FL is a derivative of triaminopyridine in the form of ethyl-N-[2-amino-6-(4-fluorophenylmethylamino) pyridin3-yl] carbamate (Fig. 1). It is commercially available as the maleate salt because FL itself is poorly water-soluble. FL is a base, with a pKa of around 5.3; it is weakly lipophilic. A key structural feature of FL is the carbamate group, which can be cleaved under strong basic and acid conditions.

\subsection{Pharmacodymanics}

Initially it was assumed that FL exerted its effect via NMDA-antagonistic activity. This theory was supported by the results of various indirect studies (Perovic et al., 1994; Osborne et al., 1998). It was later determined that FL actually interacted with G-protein-regulated, Inwardly Rectifying $\mathrm{K}^{+}$channels (GIRKs) (Jakob and Krieglstein, 1997). The GIRKs represent a newly recognised family of $\mathrm{K}^{+}$channels distinct from the voltage-dependent ones. They are regulated by neurotransmitters, occur as different subtypes and are variously expressed in different parts of the brain (Klawe and Maschke, 2009). In essence, the FL activate GIRKs Via Livornese (lato monte) 1, San Piero a Grado 56010 Pisa, Italy 
and stabilize the membrane resting potential. Therefore, FL inhibits the NMDA receptor indirectly, the $\mathrm{Mg}^{2+}$ block on the NMDA receptor remains unchanged. As the compound selectively interacts with neuronal $\mathrm{K}^{+}$, FL was offered as the prototype for a new class of drug, the "Selective Neuronal Potassium Channel Openers" (SNEPCO) (Kornhuber et al., 1999).

\subsection{Pharmacokinetics}

FL is rapidly absorbed from the gastrointestinal tract (Friedel and Fitton, 1993). Following oral administration of FL $(100 \mathrm{mg})$, the maximum plasma drug concentration (Cmax) was $0.77 \mathrm{mg} \mathrm{L}^{-1}$ in healthy volunteers, $1.12 \mathrm{mg} \mathrm{L}^{-1}$ in elderly patients and $0.72 \mathrm{mg}$ $\mathrm{L}^{-1}$ in patients with renal impairment (Abrams et al., 1988). FL at $200 \mathrm{mg}$ resulted in twice the Cmax (1.98 $\mathrm{mg} \mathrm{L}^{-1}$ ) in healthy young volunteers. Rectal administration also produced a dose dependent Cmax (Hlavica and Niebch, 1985). Absolute bioavailability for FL was 90.0 and $72.5 \%$ for oral and rectal administration, respectively (Hlavica and Niebch, 1985).

In healthy volunteers, the apparent volume of distribution for oral flupirtine $100 \mathrm{mg}$ is $154 \mathrm{~L}$. Renally impaired and elderly patients recorded higher volumes of distribution, 212 and $195 \mathrm{~L}$, respectively (Abrams et al., 1988). Binding of FL to human plasma proteins is about $80 \%$.

Flupirtine is bio-transformed in the liver into two primary metabolites, 4-fluoro-hippuric acid and the Nacetylated analogue D13223 (Fig. 1), which is pharmacologically active (about $30 \%$ of the analgesic potency of the parent drug) (Schuster et al., 1998; Methling et al., 2009). Following administration of oral FL $(100 \mathrm{mg})$, the mean terminal plasma elimination halflife is about $6.5 \mathrm{~h}$ in healthy subjects, but this is increased in patients with mild renal impairment and in the elderly to 9.8 and $14.0 \mathrm{~h}$, respectively (Abrams et al., 1988). The clearance of FL is similar in healthy and renal impaired patients $\left(275\right.$ and $263 \mathrm{~mL} \mathrm{~min}^{-1}$, respectively) but it decreases in elderly patients $(161 \mathrm{~mL}$ $\mathrm{min}^{-1}$ ) (Abrams et al., 1988). FL is predominantly excreted via the urine (72\%) (Hlavica and Niebch, 1985). FL does not undergo cytochrome P450 enzyme mediated metabolism to a significant extent (Methling et al., 2009) and human monoamine oxidase isoenzymes were considered unlikely to participate in in vivo metabolism of the drug. In contrast, human myeloperoxidase and horse radish peroxidase enzymes produced rapid turnover of FL, suggesting that this drug was an excellent substrate for these enzyme pathways (Methling et al., 2009).<smiles>CCOC(=O)Nc1ccc(NCc2ccc(F)cc2)nc1N</smiles><smiles>COC(=O)Nc1ccc(NCc2ccc(F)cc2)nc1N</smiles>

D 13223<smiles>O=C(O)CNC(=O)c1ccc(F)cc1</smiles>

Fig. 1. Molecular structure of flupirtine and its main metabolites

\subsection{Safety and Tolerability}

The most common adverse events occurring during FL therapy include drowsiness, dizziness, heartburn, headache, dry mouth, fatigue and nausea (Heusinger, 1987; Herrmann et al., 1993; 1987; McMahon et al., 1987). Such events have been reported as mild and transient, (McMahon et al., 1987) and are most likely to occur in the first 6 months of therapy (Herrmann et al., 1987). No clinically significant alterations in laboratory parameters or vital signs, including blood pressure, heart rate, ECG, renal function, haematologic and metabolic parameters, have been observed during FL therapy (Heusinger, 1987; Herrmann et al., 1993; 1987; McMahon et al., 1987). Rarely, an elevation of liver enzymes is induced and the urine may take on a greenish discoloration without any associated symptoms (Maier et al., 2010).

Compared to other available analgesics, this active ingredient is better tolerated.

The use of NSAIDs is limited by gastrointestinal adverse events, including dyspepsia, which has been reported to occur in up to $40 \%$ of NSAID recipients (Hirschowitz, 1994). 
The tolerability profile of FL is also superior to that of opioids, which can cause constipation, nausea, vomiting, sedation, confusion, pruritus, urinary retention and respiratory depression and are associated with the development of tolerance and dependence (Schug et al., 1992). No signs of dependence or tolerance were observed with FL treatment for chronic pain.

\subsection{Prospective in Veterinary Species}

Nowadays, animals (especially pets) are treated as members of the family and pet owners demand the same level of care they expect for themselves. This change in attitude has resulted in a push for the development of more effective and innovative veterinary therapies (Giorgi et al., 2012a; Giorgi and Yun, 2012). Veterinary pharmacology still has a reduced drug armamentarium compared to human pharmacology; however, human drugs are increasingly being investigated for veterinary use in order to address this shortfall (Lavy et al., 2011; Rouini et al., 2012; Giorgi et al., 2012b). This has stimulated pharmaceutical companies to market drugs developed specifically for animal use as well as academia to perform experimental studies in veterinary species with human drugs.

In this paradigm, FL has wide potential, although no studies on veterinary species are present in the literature to date. Based on what has already been reported in humans, FL could be applicable for the treatment of many forms of pain. For pain control in humans, dosages between 100 and $200 \mathrm{mg}$ t.i.d. are required (Klawe and Maschke, 2009). Given that its mechanism of action promotes neuronal rest, it has proven useful in conditions involving neuronal hyperexcitability such as chronic pain (non-malignant and malignant), migraine and neurogenic pain (Mueller-Schwefe, 2003; Luben et al., 1994; Li et al., 2008; Ringe et al., 2003; Worz et al., 1996) Furthermore, its effect as a muscle relaxant is of added value for pain associated with increased muscle tension (Worz, 1991; Worz et al., 1995). FL is also beneficial for short-term treatment of acute to moderate pain such as postoperative pain, trauma and dysmenorrhoea (Heusinger, 1987).

Chronic pain leads to nerve degeneration therefore an analgesic with neuroprotective, in addition to pain relief properties would be an advantage for the treatment of chronic pain. FL displays potent antioxidant properties in rat brain mitochondria and phaeochromocytoma 12 cell culture and administration of FL significantly inhibited free radical reactions (Gassen et al., 1998). Increasingly, veterinary patients are living longer and for this reason, there is likely to be a growing market for neuroprotective and antioxidant supplements.
Glutathione depletion is associated with a failure to maintain Reactive Oxygen Species (ROS) levels and it inevitably leads to cell death by apoptosis. FL maintains glutathione levels, a property that has prevented cell death in human RPE cells (Wood et al., 1998). This feature could be exploited in animal species that only have small amounts of this enzyme, such as cats and ferrets.

Several studies of pain-relief have made the comparison between FL and opioids.

FL was shown to be significantly more effective in pain reduction compared to pentazocine, a lower adverse effect profile was reported also (Galasko et al., 1985; Scheef, 1987; Heusinger, 1987). When administration of $100 \mathrm{mg}$ of FL and $60 \mathrm{mg}$ of dihydrocodeine in postsurgical patients were compared, both drugs showed comparable pain-reliving properties (Moore et al., 1983). FL showed a efficacy profile superior to that of tramadol for cancer-associated pain (Luben et al., 1994). FL in combinational therapy with morphine, increased the antinociceptive activity of morphine 4-fold without increasing the adverse effects (Goodchild et al., 2008). Combinatorial therapy could be useful in animals when it is desirable to avoid moderately high regimens of opioids.

Other studies compared the efficacy of FL with NSAIDs. FL and diclofenac showed equal efficacy in orthopaedic post-operative pain (Mastronardi et al., 1988) and similar efficacy in musculoskeletal pain (Marczyk, 1992). FL's reduction in pain associated with acute migraine was similar to that of paracetamol (Million et al., 1984) and patients affected by spinal root irritation reported a lower pain score with FL compared to aspirin (Sitzer, 1991).

Adverse Drug Reactions (ADR) may be dose-(type A) or non-dose-dependent type B, Hypersensitivity Drug Reactions (HDR) (Rivier and Papich, 2009). HDR to NSAIDs reportedly occur at a prevalence of $0.5-2.5 \%$ in the general population (Baumer et al., 2006). FL could be an attractive alternative for patients with a history of HDR to NSAIDs (Treudler et al., 2011). Furthermore, it does not induce the gastrointestinal side effects evoked by NSAIDs or the cardio-/cerebrovascular and renal side effects evoked with chronic therapy with coxib.

\section{CONCLUSION}

There is a substantial body of evidence on the efficacy of FL in humans however as yet, this is insufficient to recommend off-label use in veterinary clinical practice. The purpose of this manuscript is to highlight the attractiveness of FL's pharmacology profile and its potential scope for use in veterinary medicine 
with the view to encourage scientists to perform studies on FL in the veterinary field.

\section{REFERENCES}

Abrams, S.M., L.R. Baker, P. Crome, A.S. White and A. Johnston et al., 1988. Pharmacokinetics of flupirtine in elderly volunteers and in patients with moderate renal impairment. Postgrad. Med. J., 64: 361-363. PMID: 3200777

Baumer, W., S. Krekeler, V.C. DeVries, F. Niedorf and T. Tschernig et al., 2006. Non-steroidal and steroidal anti-inflammatory drugs vary in their modulation of dendritic cell function in the elicitation phase of allergic contact dermatitis. Exp. Dermatol., 15: 322-329. PMID: 16512880

Friedel, H.A. and A. Fitton, 1993. Flupirtine: A review of its pharmacological properties and therapeutic efficacy in pain states. Drugs, 45: 548-569. PMID: 7684675

Galasko, C.S., P.M. Courtenay, M. Jane and T.C. Stamp, 1985. Trial of oral flupirtine maleate in the treatment of pain after orthopaedic surgery. Curr. Med. Res. Opin., 9: 594-601. PMID: 3902375

Gassen, M., G. Pergande and M.B. Youdim, 1998. Antioxidant properties of the triaminopyridine, flupirtine. Biochem. Pharmacol., 56: 1323-1329. PMID: 9825731

Giorgi, M. and H. Yun, 2012. Pharmacokinetics of mirtazapine and its main metabolites in beagle dogs: A pilot study. Vet. J., 192: 239-241. PMID: 21652240

Giorgi, M., A. Meizler and P.C. Mills, 2012a. Pharmacokinetics of the novel atypical opioid tapentadol following oral and intravenous administration in dogs. Vet. J., 194: 309-313. DOI: 10.1016/j.tvjl.2012.05.019

Giorgi, M., G. Saccomanni, S.D. Carlo, C. Manera and E. Lavy, 2012b. Pharmacokinetics of intravenous and intramuscular parecoxib in healthy beagles. Vet. J., 193: 246-250. PMID: 22130459

Goodchild, C.S., J. Nelson, I. Cooke, M. Ashby and K. Jackson, 2008. Combination therapy with flupirtine and opioid: Open-label case series in the treatment of neuropathic pain associated with cancer. Pain Med., 9: 939-949. PMID: 18950447

Hebbes, C. and D. Lambert, 2011. Non-opioid analgesics. Anaest. Intens. Care Med., 12: 69-72. DOI: 10.1016/j.mpaic.2010.10.022

Herrmann, W.M., R. Hiersemenzel, M. Aigner, M. Lobisch and H. Riethmuller-Winzen et al., 1993. Long-term tolerance of flupirtine: Open multicenter study over one year. Fortschr. Med., 111: 266-270. PMID: 8330823
Herrmann, W.M., U. Kern and M. Aigner, 1987. On the adverse reactions and efficacy of long-term treatment with flupirtine: Preliminary results of an ongoing twelve-month study with 200 patients suffering from chronic pain states in arthrosis or arthritis. Postgrad. Med. J., 63: 87-103. PMID: 2451818

Heusinger, J.H., 1987. Efficacy and tolerance of flupirtine and pentazocine in two multicentre trials. Postgrad. Med. J., 63: 71-79. PMID: 2451817

Hirschowitz, B.I., 1994. Clinical course of nonsurgically treated zollinger-ellison syndrome. Frontiers Gastrointestinal Res., 23: 360-360.

Hlavica, P. and G. Niebch, 1985. Pharmacokinetics and biotransformation of the analgesic flupirtine in humans. Arzneimittelforschung., 35: 67-74. PMID: 4039154

Jakob, R. and J. Krieglstein, 1997. Influence of flupirtine on a G-protein coupled inwardly rectifying potassium current in hippocampal neurones. Br. J. Pharmacol., 122: 1333-1338. PMID: 9421279

Klawe, C. and M. Maschke, 2009. Flupirtine: Pharmacology and clinical applications of a nonopioid analgesic and potentially neuroprotective compound. Exp. Opin. Pharmacother., 10: 1495500. PMID: 19505216

Kornhuber, J., S. Bleich, J. Wiltfang, M. Maler and C.G. Parsons, 1999. Flupirtine shows functional NMDA receptor antagonism by enhancing $\mathrm{Mg}^{2+}$ block via activation of voltage independent potassium channels. J. Neural. Transm., 106: 857-867. PMID: 10599868

Lavy, E., U. Prise, G. Soldani, D. Neri and N. Brandriss et al., 2011. Pharmacokinetics of methylphenidate after oral administration of immediate and sustained-release preparations in beagle dogs. Vet. J., 189: 336-340. PMID: 20696604

Li, C., J. Ni, Z. Wang, M. Gasparic and B. Terhaag et al., 2008. Analgesic efficacy and tolerability of flupirtine vs. tramadol in patients with subacute low back pain: A double-blind multicentre trial. Curr. Med. Res. Opin., 24: 3523-3530. PMID: 19032134

Luben, V., H. Muller, M. Lobisch and R. Worz, 1994. Treatment of tumor pain with flupirtine: Results of a double-blind study versus tramadol. Fortschr. Med., 112: 282-286. PMID: 7927099

Maier, A., Y. Liu, A. Scholze, T.H. Westhoff and M. Tepel, 2010. Green urine following exposure to flupirtine. Am. J. Kidney Dis., 56: 1014-1015. PMID: 20970027 
Marczyk, L.R.S., 1992. Avaliacao comparativa do maleato de flupirtina versus diclofenaco potassico em afeccoes musculo-esqueleticas. Arq. Bras. Med., 66: 269-275.

Mastronardi, P., M. D’Onofrio, E. Scanni, M. Pinto and S. Frontespezi et al., 1988. Analgesic activity of flupirtine maleate: A controlled double-blind study with diclofenac sodium in orthopaedics. J. Int. Med. Res., 16: 338-348. PMID: 3058538

McMahon, F.G., W.F. Arndt Jr., J.J. Newton, P.A. Montgomery and J.L. Perhach, 1987. Clinical experience with flupirtine in the U.S. Postgrad. Med. J., 63: 81-85. PMID: 3328854

Methling, K., P. Reszka, M. Lalk, O. Vrana and E. Scheuch et al., 2009. Investigation of the in vitro metabolism of the analgesic flupirtine. Drug Metab. Dispos., 37: 479-493. PMID: 19074524

Million, R., B.R. Finlay and J.R. Whittington, 1984. Clinical trial of flupirtine maleate in patients with migraine. Curr. Med. Res. Opin., 9: 204-212. PMID: 6389014

Moore, R.A., R.E. Bullingham, S. Simpson, G. O'Sullivan and P.J. Evans et al., 1983. Comparison of flupirtine maleate and dihydrocodeine in patients following surgery. Br. J. Anaesth., 55: 429-432. PMID: 6342637

Mueller-Schwefe, G., 2003. Flupirtine in acute and chronic pain associated with muscle tenseness: Results of a postmarket surveillance study. Fortschr. Med. Orig., 121: 11-18. PMID: 15117064

Osborne, N.N., C. Cazevieille, J.P. Wood, M.S. Nash and G. Pergande et al., 1998. Flupirtine, a nonopioid centrally acting analgesic, acts as an NMDA antagonist. Gen. Pharmacol., 30: 255-263. PMID: 9510072

Perovic, S., C. Schleger, G. Pergande, S. Iskric and H. Ushijima et al., 1994. The triaminopyridine flupirtine prevents cell death in rat cortical cells induced by N-methyl-D-aspartate and gp120 of HIV-1. Eur. J. Pharmacol., 288: 27-33. PMID: 7705465

Ringe, J.D., D. Miethe, D. Pittrowm and K. Wegscheider, 2003. Analgesic efficacy of flupirtine in primary care of patients with osteoporosis related pain: A multivariate analysis. Arzneimittelforschung, 53: 496-502. PMID: 12918215
Rivier, J.E. and M.G. Papich, 2009. Veterinary Pharmacology and Therapeutics. 9th Edn., John Wiley and Sons, Ames, Iowa, ISBN-10: 0813820618, pp: 1500.

Rouini, M.R., H. Lavasani, B. Sheikholeslami, V. Nikoui and A. Bakhtiarian et al., 2012. Pharmacokinetics of mirtazapine and its main metabolites after single oral administration in fasting/fed horses. J. Equine Vet. Sci., DOI:1 0.1016/j.jevs.2012.07.016

Scheef, W., 1987. Analgesic efficacy and safety of oral flupirtine in the treatment of cancer pain. Postgrad. Med. J.,3: 67-70. PMID: 2451816

Schug, S.A., D. Zech and S. Grond, 1992. Adverse effects of systemic opioid analgesics. Drug Saf., 7: 200-213. PMID: 1354445

Schuster, G., M. Schwarz, F. Block, G. Pergande and W.J. Schmidt, 1998. Flupirtine: A review of its neuroprotective and behavioral properties. CNS Drug Rev., 4: 149-164. DOI: 10.1111/j.15273458.1998.tb00061.x

Sitzer, G., 1991. Einfacblindstudie mit Flupirtin gegen Acetylsalicylsaure bei Patienten mit spinalemWurzelreizsyndrom.

Orthopadie/Traumatol., 6: 37-42.

Treudler, R., K. Pohle and J.C. Simon, 2011. Flupirtine is a safe alternative drug in patients with hypersensitivity to NSAIDs. Eur. J. Clin. Pharmacol., 67: 961-963. PMID: 21387166

Wood, J.P., G. Pergande and N.N. Osborne, 1998. Prevention of glutathione depletion-induced apoptosis in cultured human RPE cells by flupirtine. Restor. Neurol. Neurosci., 12: 119-125. PMID: 12671306

Worz, R., 1991. Flupirtine in chronic myofascial pain conditions. Fortschr. Med., 109: 158-160. PMID: 2045042

Worz, R., M. Lobisch, B. Schwittmann, M. Gessler and K.H. Grotemeyer et al., 1995. Effectiveness of flupirtine in chronic tension headache: Results of a double-blind study versus placebo. Fortschr. Med., 113: 463-468. PMID: 8543273

Worz, R., W. Bolten, B. Heller, J.U. Krainick and G. Pergande, 1996 Flupirtine in comparison with chlormezanone in chronic musculoskeletal back pain: Results of a multicenter randomized doubleblind study. Fortschr. Med., 114: 500-504. PMID: 9119352 